\title{
Potential drawbacks in cell-assisted lipotransfer: A systematic review of existing reports (Review)
}

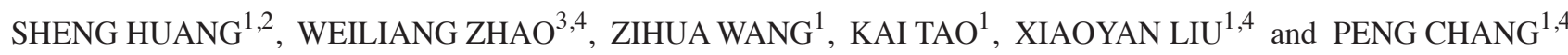 \\ ${ }^{1}$ Department of Plastic and Reconstructive Surgery, General Hospital of Shenyang Military Area Command, \\ Shenyang, Liaoning 110840; ${ }^{2}$ Department of General Surgery, Fuzhou General Hospital of Nanjing Command, Fuzhou, \\ Fujian 350025; ${ }^{3}$ Department of Anesthesiology, Changzheng Hospital, Second Military Medical University, \\ Shanghai 200003; ${ }^{4}$ Second Military Medical University, Shanghai 110840, P.R. China
}

Received January 26, 2015; Accepted November 17, 2015

DOI: $10.3892 / \mathrm{mmr} .2015 .4682$

\begin{abstract}
Cell-assisted lipotransfer (CAL) has been widely used in various clinical applications, including breast augmentation following mammectomy, soft-tissue reconstruction and wound healing. However, the clinical application of CAL has been restricted due to the transplanted fat tissues being readily liquefied and absorbed. The present review examines 57 previously published studies involving CAL, including fat grafting or fat transfer with human adipose-stem cells in all known databases. Of these 57 articles, seven reported the clinical application of CAL. In the 57 studies, the majority of the fat tissues were obtained from the abdomen via liposuction of the seven clinical studies, four were performed in patients requiring breast augmentation, one in a patient requiring facial augmentation, one in a patient requiring soft tissue augmentation/reconstruction and one in a patient requiring fat in their upper arms. Despite the potential risks, there has been an increased demand for CAL in in cosmetic or aesthetic applications. Thus, criteria and guidelines are necessary for the clinical application of CAL technology.
\end{abstract}

\section{Contents}

1. Introduction

2. Background

Correspondence to: Dr Kai Tao or Dr Peng Chang, Department of Plastic and Reconstructive Surgery, General Hospital of Shenyang Military Area Command, 83 Wenhua Road, Shenhe, Shenyang, Liaoning 110840, P.R. China

E-mail: taokaizx123@163.com

E-mail: cp17625@hotmail.com

Abbreviations: CAL, cell-assisted lipotransfer; ASCs, adipose-derived stem cells

Key words: cell-assisted lipotransfer, adipose-derived stem cells, plastic surgery
3. Publication review

4. Risks of isolation and expansion of ASCs

5. Potential risks of the clinical application of CAL

6. Postoperative safety evaluation

7. Long-term follow-up of the effects of CAL

8. Conclusion

\section{Introduction}

Autologous fat transfer refers to the transplantation of fat tissue from one part of the body to another part of the body. Along with the development of the tumescent liposuction technique, autologous fat transfer has been widely used in various clinical applications, including breast augmentation, soft-tissue reconstruction and wound healing (1-3). However, the transplanted adipose tissue cannot tolerate hypoxia, is readily liquefied and the majority is, therefore, the clinical use of lipotransfer is limited (4). In previous years, adipose-derived stem cells (ASCs) have been identified and isolated from adipose tissue. Significant progress has been made from the characterization of ASCs to their application clinically. A cell-assisted lipotransfer (CAL) has been developed, in which ASCs purified from half of harvested fat tissue are mixed with another half, prior to being microinjected into the desired parts of a patient's body. Mixing the ASCs with fat cells augments the generation of blood vessels and the survival rate of the transplanted fat cells. It has been reported that the survival rate of transplanted fat cells is increased by $35 \%$ when CAL is used alone, and increases further when CAL is used with hyaluronic acid as the carrier, or when used with stents $(5,6)$. Subsequently, an increasing number of basic investigations, and those investigating the clinical application of CAL, have been performed worldwide. The present review aims to present the current status of CAL, including the isolation and identification of ASCs, clinical application of CAL and the long-term follow-up of the clinical application of CAL, with emphasis on the potential risks of CAL technology. The aim of the present review is to indicate the importance to plastic surgeons to standardize CAL for patients having cosmetic surgery or those with aesthetic requirements. 


\section{Background}

Basics of ASCs. ASCs are a specific branch of stem cells (Fig. 1), which are adult stem cells in fat tissues and exhibit the following features (7): They can self-renew and have multi-potent differentiation capacity. Furthermore, they can be readily expanded in vitro and in vivo, thus being an ideal cell source for autologous cell transplantation. They can promote angiogenesis, which is essential for the survival of transplanted adipose tissues, as these tissues are particularly sensitive to hypoxia and, as liposuction is widely used in plastic surgery, ASCs can be readily obtained.

Basic concepts of lipotransfer and CAL. Autologous lipotransfer, also termed fat transplantation, was first used by a German physician, Franz Neuber, in 1893 (8). Since then, it has been widely used in the several areas, including facial rejuvenation, soft-tissue reconstruction and wound healing (9). However, several problems remain, which require addressing prior to its extensive clinical application. These problems include the following: i) Fat cells cannot tolerate hypoxia (10); ii) transplanted fat tissue is readily liquefied, possibly due to the hypoxia or another change in environment (11); iii) transplanted fat grafts can lose $20-90 \%$ of their volume over time due to tissue absorption (12); iv) aged fat cells do not regenerate and are gradually absorbed, even if a large section of fat tissue or a large number of fat cells are used for transplantation (13).

In the majority of reported autologous lipotransfer procedures, composite tissue flaps were used. These composite tissue flaps contain blood vessels, which are important for the survival of grafted tissue; however, obtaining one or more composite tissue flaps for transplantation often leads to donor-site defect and requires costly surgical procedures $(14,15)$. CAL uses purified ASCs mixed with fat cells for cell transplantation; the ASCs used in CAL promote the regeneration of blood vessels at the graft site, improving the survival rate of transplanted fat cells (16). This novel technology has increased the potential of fat grafting (17).

\section{Publication review}

The PubMed database (http://www.ncbi.nlm.nih.gov/pubm $\mathrm{ed} /$ ?cmd=HistorySearch\&querykey=10) was examined between the date of its inception and January 2000, using the following combination of keywords: 'Human adipose stem cells' OR 'human adipose-derived stem cells' OR 'human adipose-derived stem cells' OR 'human stromal vascular fraction stem cells' AND 'cell assisted lipotranfer' OR 'fat grafting' OR 'fat transfer.' A total of 57 published studies were selected for evaluation.

\section{Risks of isolation and expansion of ASCs}

Current status of the isolation and expansion of ASCs. The isolation of ASCs from adipose tissues was developed by Rodbell and Jones in the 1960s $(18,19)$. Initially, fat grafts were cut into small pieces to release fat cells, whereas later, the invention of liposuction technology simplified this process. Liposuction is a procedure in which a plastic surgeon injects saline containing anesthetic and/or adrenaline into the subcutaneous adipose tissue, and then removes a mixture containing adipose cells and cell debris through suction (20). This procedure is composed of several steps, and each step can affect the quantity and quality of ASCs, including i) crushing of the adipose tissue, in which Atala et al (21) found that the crushing of adipose tissues, which is affected by the diameter of the suction cannula, affects the viability of isolated ASCs. Other studies have indicated that aspiration liposuction alone does not significantly alter the viability of isolated ASCs (21-23); ii) centrifugation speed, in which the recovery of ASCs may be improved further by manipulating the centrifugation speed used in the ASC purification process. The optimal centrifugation speed is $1,200 \mathrm{~g}(24,25)$. iii) Patient age, as the differentiation capacity of ASCs varies with the age of the patient, with younger patients having higher ASC differentiation capacity (26); iv) Site of ASC isolation. ASCs from the abdomen appear to have a higher yield, compared with those from the hip or thigh (27); v) the washing step in ASC purification, which is necessary for the purification of ASCs (28). This step is performed to remove the blood contaminants, however, it does not affect the integrity or number of adipocytes, and allows the recovery of a larger number of endothelial cells and ASCs.

Other strategies have also been developed to improve the isolation of ASCs. These strategies include fluorescence-activated cell sorting (29), immunomagnetic beads coated with specific antibodies (30) and selecting for the expression of aldehyde dehydrogenase (31). The methods used in isolating ASCs may affect the quantity and quality of ASCs.

Potential risks during the isolation and expansion of ASCs. The following potential risks may occur during the isolation and expansion of ASCs: i) Disease transmission, isolated ASCs are usually expanded in growth medium supplemented with $10 \%$ fetal bovine serum (FBS), however, FBS may cause disease transmission (32). Several groups have attempted to composite a cell-free medium for the expansion of ASCs. Parker et al (33) successfully developed a complete serum-free medium, in which human ASCs were rapidly expanded and used for human clinical trials. ii) Immunosuppression, previous studies have found that, like bone marrow stem cells, ASCs may have immunosuppressive properties and, although their immunosuppressive function may be a useful property for transplantation, it also introduces a potential risk of allowing occult cancer to evade immune surveillance (34). Therefore, prior to any large-scale human trials of CAL, the safety and efficacy of CAL requires confirmation.

Mistress on identification procedure. ASCs share $>90 \%$ of their surface markers with mesenchymal stem cells, pericytes and smooth muscle stem cells (35). The surface markers of ASCs are most likely altered with changes in cell density or passage number (36). ASCs express relatively higher levels of CD117, HLA-DR and CD34, which are surface markers for other adult stem cells, as compared with bone marrow-derived stem cells (37-39). ASCs also express low levels of CD13, CD29, CD44, CD63, CD73, CD90, CD166 and CD105, which are surface markers for stromal cells. In a previous study, it was observed that $10-20 \%$ of ASCs expressed CD34 for 20 weeks in culture (20). At present, the unique surface markers for 
ASCs remain to be elucidated, and there is no efficient method of isolating ASCs from adipose tissues. Therefore, obtaining pure ASCs remains a challenge for scientists (40). Methods used to track cells in vivo over time in a non-invasive manner, for example, using super paramagnetic iron oxide particle labeling (41) require development. Genetic markers, including luciferase and enhanced green fluorescent protein have been integrated into the genomes of ASCs mediated with viral vectors and/or nucleoporation, achieving 30-60\% labeling efficiency. Other labeling options include the use of the $\mathrm{PKH}$ and 1,1'-dioctadecyl-3,3,3',3'-tetramethylindocarbocyanine family of dyes $(42,43)$.

\section{Potential risks of the clinical application of CAL}

Clinical application of CAL. CAL is a newly developed technology, in which the patients' own stromal vascular fraction (SVF), which is rich in ASCs, is isolated from half of aspirated fat and mixed with another half, prior to the mixture being injected into the desired parts of the body. Adding SVF into the aspirated fat, which is low in ASCs, converts it into fat-rich ASCs. Preliminary results (Table I) have suggested that CAL is an effective and safe technology for soft-tissue augmentation, and is superior to conventional lipoinjection (44).

Modified CALs have also been reported. Kang et al (45) developed an in vitro 3D model for tissue regeneration. In this model, human vascularized adipose tissue, human ASCs and human umbilical vein endothelial cells were co-cultured on 3D aqueous silk scaffolds. Following 2 weeks of co-culture, continuous endothelial lumens formed. Zuk et al (46) placed ASCs in a well sealed, biocompatible polymer stent to generate hypoxic conditions, and the ASCs secreted growth factors and other chemicals, which stimulated the growth of new capillaries in the fat tissue, even following the cell transplantation. Novel synthetic bio-materials, including peptides, biodegradable polymers and materials used for other stem cells, can be used to change the pattern of adhesion molecules on the surface of local adipose cells, to allow differentiation of the adipose tissue (47).

Remaining questions associated with the clinical application of $C A L$. The therapeutic effect of CAL in cosmetics and aesthetics remains controversial, most likely due to the lack of a standard method for isolating pure ASCs. At present, the explanation for why adding ASCs to adipose tissues for transplantation allows improved grafting, compared with using adipose tissue only, remains to be elucidated. Quantitative and qualitative investigations, comparing the therapeutic effects of using pure ASCs and a mixture of ASCs with certain types of fat components or other components are required to confirm the previous conclusion. Certain studies have hypothesized that the robust ectopic adipogenesis of ASCs in vivo relies on their predifferentiation induced in vitro prior to their transplantation $(48,49)$. The induced differentiation of ASCs in vitro may be replaced by supplying adipogenic stimuli to transplanted ASCs, in a process referred to as in situ adipogenesis.

The therapeutic effects of CAL may be due to the trans-differentiation of functionally mature cells from ASCs or by the paracrine secreted from ASCs. Previous studies have suggested that trans-differentiation may not be essential, as it is unlikely that ASCs are trans-differentiated to functionally mature cells in such a short period of time following ASC transplantation $(50,51)$. The debate on these questions is likely to continue if the factors controlling the self-renewal and differentiation of ASCs, and other chronic effects from the transplantation of ASCs are not addressed. Considering the complex environment in which ASCs exist in human body, current knowledge of ASCs remains immature in scope (52).

The limited proliferation capacity of ASCs also prevents their widespread clinical use. ASCs lack telomerase and their telomeres are short; thus they can only proliferate in vitro for a limited period of time (53). Studies have shown that the ASCs isolated from aged patients have reduced proliferation capacity and stability $(54,55)$. Therefore, it is reasonable to perform allografts using the ASCs from younger individuals.

Other questions require addressing prior to CAL being used widely in clinical settings, including: i) How the proliferation and differentiation process of ASCs can be regulated in vitro and in vivo; ii); which factors control the proliferation and differentiation of ASCs; iii) the predominant factors controlling the proliferation and differentiation process of ASCs; iv) which factors stimulate ASCs to secrete paracrine factors; v) whether transplanted ASCs are tumorigenic; and VI) what causes ASCs to become liquefied in vivo. Therefore, several questions require answering if CAL is to be widely used clinically.

\section{Postoperative safety evaluation}

Necroses and liquefaction of transplanted adipose tissues. The most common complications of lipotransfer are liquefaction and necrosis of adipose tissue grafts (56). The mechanisms underlying these complications remain to be elucidated and have attracted significant concern (57). So far, there is no clear evidence that the incidence of liquefaction is correlated with the CAL process, however, rigorous investigations with appropriate statistical analysis of data are required to confirm this.

Bacterial contamination. Bacterial contamination can occur during any step of CAL, including when ASCs are prepared and stored for commercial purposes. Bacterial contamination during CAL causes early complications, including transplantation, septicemia and other safety concerns (2). In 2010, de la Fuente et al (58) failed to duplicate previous experiments, in which it was claimed that certain human adipose-derived mensenchymal stem cells were spontaneously transformed into cancer stem cells. The authors suggested that the spontaneous transformation of human ASCs may have been caused by cross-contamination. Bacterial contamination requires prevention by strict accordance to guidelines for professional safety and for admittance of patients.

Further surgical procedures. For certain patients receiving CAL, a second or further surgical procedures may be required if they are not satisfied with the results. At present, there are no specific criteria to objectively appraise the outcome of CAL. In addition, there is insufficient data to allow comparison of the outcomes of single and multiple CALs.

Postoperative psychological assessment. The psychological reactions of the patients receiving CAL also require consideration. A patient's expectations of CAL, the psychological care of 


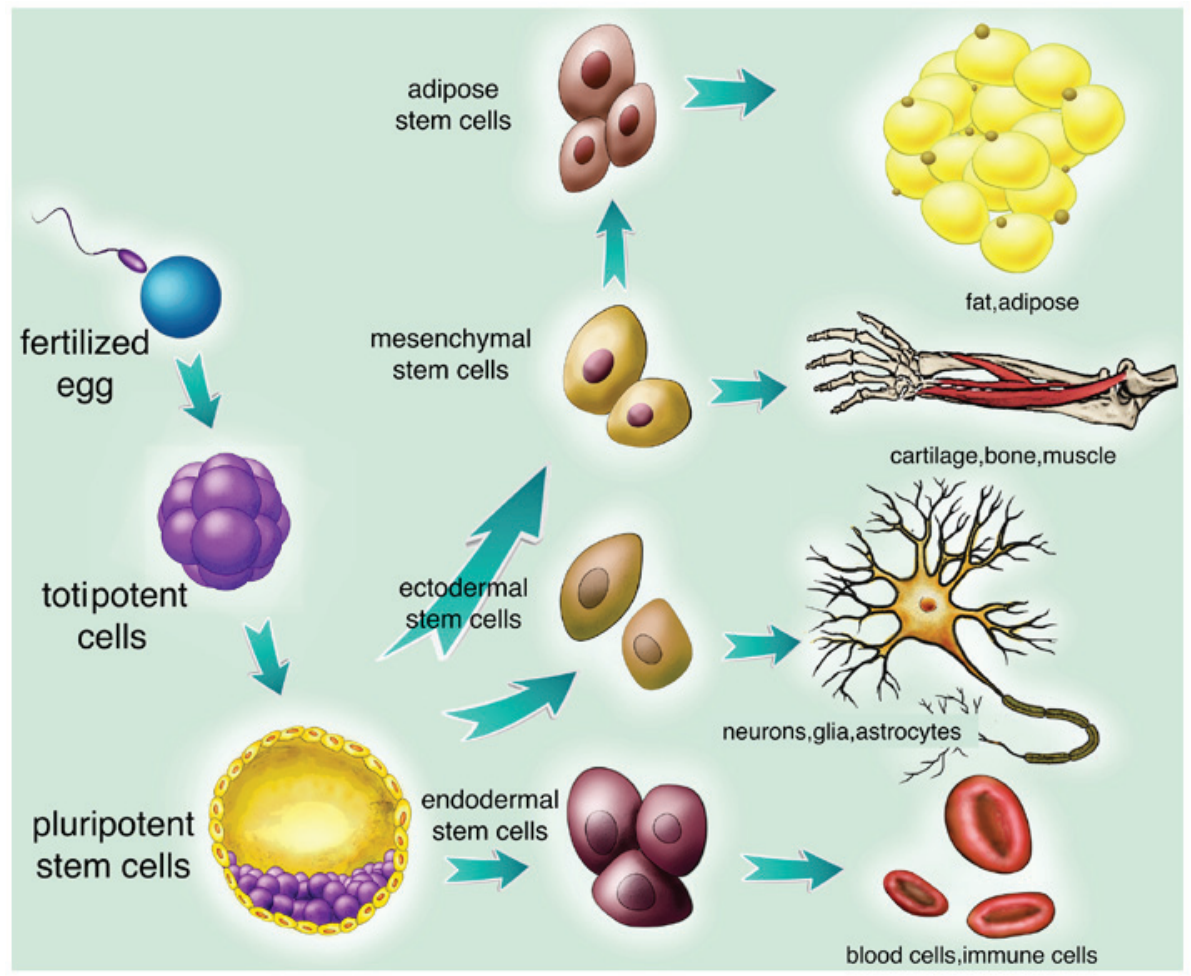

Figure 1. Branches of different types of adult and stem cells.

a patient following CAL and the self-satisfaction of a patient can affect the outcome of the CAL procedure. Therefore, effective communication between doctors and patients, and useful guidance for patients' mental health is required to avoid problems, and requires reinforcement prior to any large-scale clinical application of CAL being performed.

Emergency plans to deal with complications. CAL technology has been used extensively to assist patients in achieving their cosmetic or aesthetic requirements worldwide (59). However, there is a lack of experience required to deal with the potential risks mentioned above. Therefore, it is necessary to devise emergency plans for these unforeseeable risks to provide effective provisional measures in case of emergency, and accumulate experience, which can be used to deal with the potential risks of CAL procedures.

\section{Long-term follow-up of the effects of CAL}

Postoperative follow-up. A postoperative follow-up system is required for large-scale clinical trials, as there is currently no such system to meet this requirement. However, there has been progress in this area. In the United States, between 1995 and 2000, Coleman and Saboeiro (60) applied CAL to the breasts of 17 patients, following which the size and shape of the patients' breasts were considered significantly improved. A long-term retrospective study on these patients confirmed that CAL permanently repaired the local soft tissue defects, however, the most common complications, necroses and liquefaction of the transplanted adipose tissues, remained. In Japan, Yoshimura et al (44) reported that CAL was used to effectively augment the breasts of 40 women; and claimed that CAL was superior to conventional lipotransfer.
A comprehensive system is required, which can be used to accurately assess the outcomes of CAL technology. This system requires criteria for postoperative evaluation, comprehensive risk assessment and solution, and a cooperative research center, which is in charge of collecting data from randomized double-blind placebo-controlled trials. Finally, as CAL techniques require constant improvement, evidence-based medicine may be considered to evaluate therapeutic efficacy.

\section{Conclusion}

In conclusion, although CAL technology has been applied in the treatment of patients with cosmetic and aesthetic requirements in several countries, there remains no efficient means to purify ASCs from fat tissues.

International multi-center randomized controlled trial system. The majority of studies investigating the use of CAL have been performed in vitro or in animal models, therefore, the clinical application of CAL in humans remains in the early stages. It is necessary to perform double-blind randomized controlled trials in a planned manner in order to obtain sufficient data for evidence-based medicine analysis. An international co-operation for such clinical trials, is recommended in order to provide enough patients for involvement in the trials. This action requires the coordination of multi-center laboratories around the world; with all laboratories involved in the trails following the same criteria and guidelines for CAL. This may be the only way that the safety of CAL for use in patients with cosmetic and aesthetic requirements can be assessed.

Criteria and guidelines for clinical application. Although there are several risks associated with using CAL in patients, 


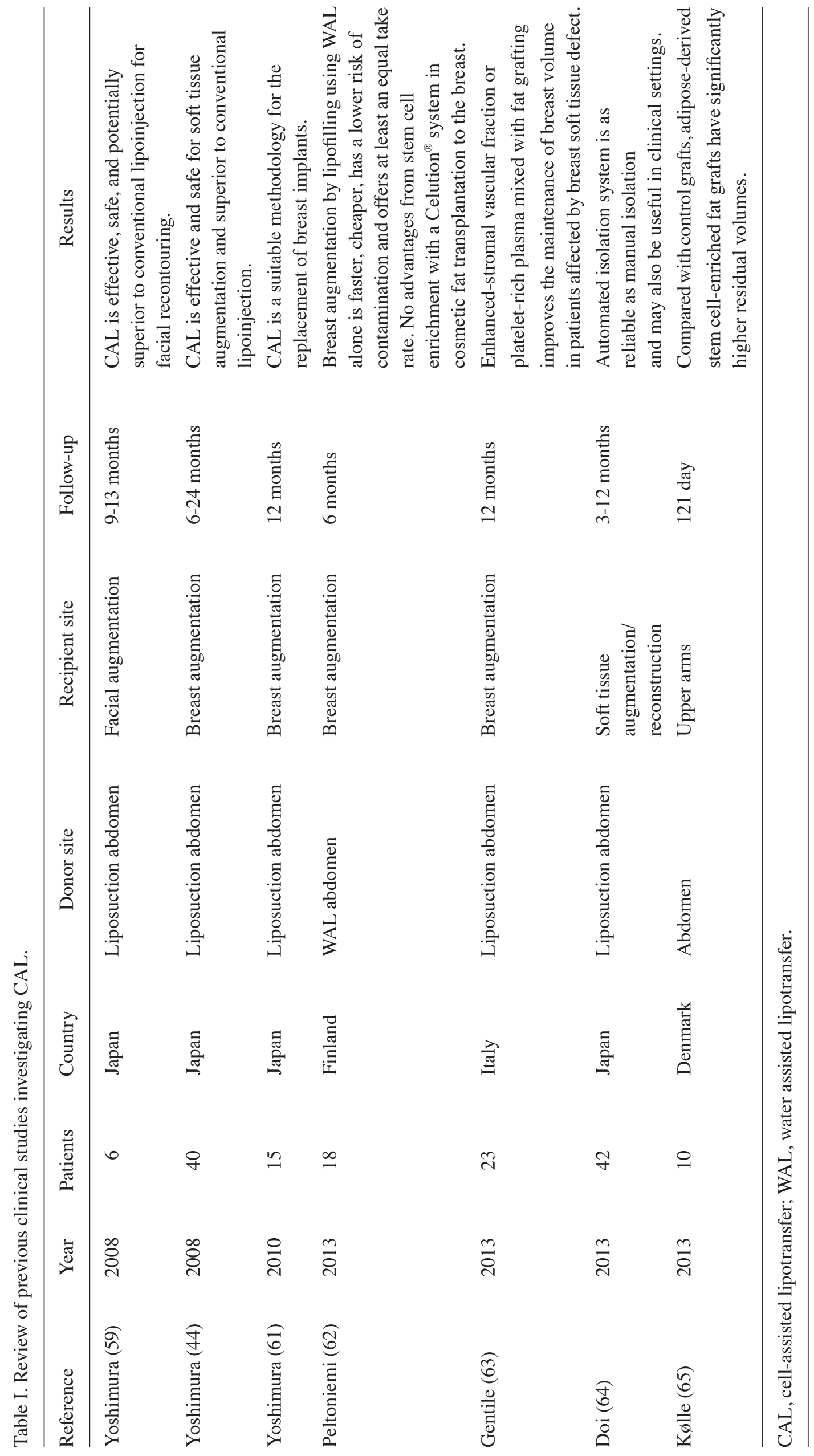


CAL technology provides a promising means to treat patients with cosmetic or aesthetic requirements. The outcome of the present review suggested that ideal CAL technology requires pain and injury to be reduced when fat cells are obtained from patients, the ability of ASCs to be readily isolated and expanded in vitro, the ability of differentiation of ASCs to be controlled, a safe and effective transplantation procedure, and the use of practical guidelines for the large-scale manufacture of ASCs.

\section{Acknowledgements}

This review was funded by the Natural Science Foundation of Liaoning province, China (grant nos. 2009225019 and 2011225021).

\section{References}

1. Schweizer R, Tsuji W, Gorantla VS, Marra KG, Rubin P and Plock JA: The role of adipose-derived stem cells in breast cancer progression and metastasis. Stem Cells Int 2015: $120949,2015$.

2. Hoppe DL, Ueberreiter K, Surlemont Y, Peltoniemi H, Stabile M and Kauhanen S: Breast reconstruction de novo by water-jet assisted autologous fat grafting - a retrospective study. Ger Med Sci 11: Doc17, 2013.

3. Banyard DA, Salibian AA, Widgerow AD and Evans GR: Implications for human adipose-derived stem cells in plastic surgery. J Cell Mol Med 19: 21-30, 2015.

4. Hamid AA, Idrus RB, Saim AB, Sathappan S and Chua KH: Characterization of human adipose-derived stem cells and expression of chondrogenic genes during induction of cartilage differentiation. Clinics (Sao Paulo) 67: 99-106, 2012

5. Matsumoto D, Sato K, Gonda K, Takaki Y, Shigeura T, Sato T, Aiba-Kojima E, Iizuka F, Inoue K, Suga $H$ and Yoshimura K: Cell-assisted lipotransfer: Supportive use of human adipose-derived cells for soft tissue augmentation with lipoinjection. Tissue Eng 12: 3375-3382, 2006.

6. Stillaert FB, Di Bartolo C, Hunt JA, Rhodes NP, Tognana E, Monstrey S and Blondeel PN: Human clinical experience with adipose precursor cells seeded on hyaluronic acid-based spongy scaffolds. Biomaterials 29: 3953-3959, 2008.

7. Gruber RP and Jazayeri L: Discussion. Effects of adipose-derived stem cells on improving the viability of diced cartilage grafts. Plast Reconstr Surg 129: 378-379, 2012.

8. Mizuno H, Itoi Y, Kawahara S, Ogawa R, Akaishi S and Hyakusoku H: In vivo adipose tissue regeneration by adipose-derived stromal cells isolated from GFP transgenic mice. Cells Tissues Organs 187: 177-185, 2008.

9. Deng B, Wen J, Ding Y, Peng J and Jiang S: Different regulation role of myostatin in differentiating pig ADSCs and MSCs into adipocytes. Cell Biochem Funct 30: 145-150, 2012.

10. Rueda-Clausen CF, Dolinsky VW, Morton JS, Proctor SD, Dyck JR and Davidge ST: Hypoxia-induced intrauterine growth restriction increases the susceptibility of rats to high-fat diet-induced metabolic syndrome. Diabetes 60: 507-516, 2011

11. Eirin A, Zhu XY, Krier JD, Tang H, Jordan KL, Grande JP, Lerman A, Textor SC and Lerman LO: Adipose tissue-derived mesenchymal stem cells improve revascularization outcomes to restore renal function in swine atherosclerotic renal artery stenosis. Stem Cells 30: 1030-1041, 2012.

12. Cherubino M and Marra KG: Adipose-derived stem cells for soft tissue reconstruction. Regen Med 4: 109-117, 2009.

13. Chien MH, Bien MY, Ku CC, Chang YC, Pao HY, Yang YL, Hsiao M, Chen CL and Ho JH: Systemic human orbital fat-derived stem/stromal cell transplantation ameliorates acute inflammation in lipopolysaccharide-induced acute lung injury. Crit Care Med 40: 1245-1253, 2012

14. Shenaq SM and Yuksel E: New research in breast reconstruction: Adipose tissue engineering. Clin Plast Surg 29. 111-125, 2002.

15. Langstein HN and Robb GL: Reconstructive approaches in soft tissue sarcoma. Semin Surg Oncol 17: 52-65, 1999.
16. Trojahn Kølle SF, Oliveri RS, Glovinski PV, Elberg JJ, Fischer-Nielsen A and Drzewiecki KT: Importance of mesenchymal stem cells in autologous fat grafting: A systematic review of existing studies. J Plast Surg Hand Surg 46: 59-68, 2012.

17. Sterodimas A, de Faria J, Nicaretta B and Pitanguy I: Tissue engineering with adipose-derived stem cells (ADSCs): Current and future applications. J Plast Reconstr Aesthet Surg 63: 1886-1892, 2010.

18. Mayr M and Xu Q: Smooth muscle cell apoptosis in arteriosclerosis. Exp Gerontol 36: 969-987, 2001.

19. Tukaj C, Bohdanowicz J and Kubasik-Juraniec J: The growth and differentiation of aortal smooth muscle cells after calcitriol treatment are associated with microtubule reorganisation-an in vitro study. Folia Morphol (Warsz) 63: 51-57, 2004.

20. Yoshimura K, Shigeura T, Matsumoto D, Sato T, Takaki Y, Aiba-Kojima E, Sato K, Inoue K, Nagase T, Koshima I and Gonda K: Characterization of freshly isolated and cultured cells derived from the fatty and fluid portions of liposuction aspirates. J Cell Physiol 208: 64-76, 2006.

21. Atala A, Bauer SB, Soker S, Yoo JJ and Retik AB: Tissue-engineered autologous bladders for patients needing cystoplasty. Lancet 367: 1241-1246, 2006.

22. Jack GS, Zhang R, Lee M, Xu Y, Wu BM and Rodríguez LV: Urinary bladder smooth muscle engineered from adipose stem cells and a three dimensional synthetic composite. Biomaterials 30: 3259-3270, 2009.

23. Sievert KD, Amend B and Stenzl A: Tissue engineering for the lower urinary tract: A review of a state of the art approach. Eur Urol 52: 1580-1589, 2007.

24. Kim YM, Jeon ES, Kim MR, Jho SK, Ryu SW and Kim JH: Angiotensin II-induced differentiation of adipose tissue-derived mesenchymal stem cells to smooth muscle-like cells. Int J Biochem Cell Biol 40: 2482-2491, 2008.

25. Coleman SR: Structural fat grafting: More than a permanent filler. Plast Reconstr Surg 118 (Suppl 3): S108-S120, 2006.

26. Schipper BM, Marra KG, Zhang W, Donnenberg AD and Rubin JP: Regional anatomic and age effects on cell function of human adipose-derived stem cells. Ann Plast Surg 60: 538-544, 2008.

27. Jurgens WJ, Oedayrajsingh-Varma MJ, Helder MN, Zandiehdoulabi B, Schouten TE, Kuik DJ, Ritt MJ and van Milligen FJ: Effect of tissue-harvesting site on yield of stem cells derived from adipose tissue: Implications for cell-based therapies. Cell Tissue Res 332: 415-426, 2008.

28. Condé-Green A, de Amorim NF and Pitanguy I: Influence of decantation, washing and centrifugation on adipocyte and mesenchymal stem cell content of aspirated adipose tissue: A comparative study. J Plast Reconstr Aesthet Surg 63: 1375-1381, 2010.

29. Suga H, Matsumoto D, Eto H, Inoue K, Aoi N, Kato H, Araki J and Yoshimura K: Functional implications of CD34 expression in human adipose-derived stem/progenitor cells. Stem Cells Dev 18: 1201-1210, 2009

30. Rada T, Reis RL and Gomes ME: Novel method for the isolation of adipose stem cells (ASCs). J Tissue Eng Regen Med 3: 158-159, 2009.

31. Mitchell JB, McIntosh K, Zvonic S, Garrett S, Floyd ZE, Kloster A, Di Halvorsen Y, Storms RW, Goh B, Kilroy G, et al: Immunophenotype of human adipose-derived cells: Temporal changes in stromal-associated and stem cell-associated markers. Stem Cells 24: 376-385, 2006.

32. Locke M, Windsor J and Dunbar PR: Human adipose-derived stem cells: Isolation, characterization and applications in surgery. ANZ J Surg 79: 235-244, 2009.

33. Parker A, Shang H, Khurgel M and Katz A: Low serum and serum-free culture of multipotential human adipose stem cells. Cytotherapy 9: 637-646, 2007.

34. Hsiao ST, Asgari A, Lokmic Z, Sinclair R, Dusting GJ, Lim SY and Dilley RJ: Comparative analysis of paracrine factor expression in human adult mesenchymal stem cells derived from bone marrow, adipose and dermal tissue. Stem Cells Dev 21: 2189-2203, 2012.

35. Traktuev DO, Merfeld-Clauss S, Li J, Kolonin M, Arap W, Pasqualini R, Johnstone BH and March KL: A population of multipotent CD34-positive adipose stromal cells share pericyte and mesenchymal surface markers, reside in a periendothelial location and stabilize endothelial networks. Circ Res 102: 77-85, 2008. 
36. Nakagami H, Morishita R, Maeda K, Kikuchi Y, Ogihara T and Kaneda Y: Adipose tissue-derived stromal cells as a novel option for regenerative cell therapy. J Atheroscler Thromb 13: 77-81, 2006.

37. Reich CM, Raabe O, Wenisch S, Bridger PS, Kramer M and Arnhold S: Isolation, culture and chondrogenic differentiation of canine adipose tissue-and bone marrow-derived mesenchymal stem cells-a comparative study. Vet Res Commun 36: 139-148, 2012.

38. Bailey AM, Kapur S and Katz AJ: Characterization of adipose-derived stem cells: An update. Curr Stem Cell Res Ther 5: 95-102, 2010.

39. Tsuji W, Rubin JP and Marra KG: Adipose-derived stem cells: Implications in tissue regeneration. World J Stem Cells 6: 312-321, 2014.

40. Wolbank S, Peterbauer A, Wassermann E, Hennerbichler S, Voglauer R, van Griensven M, Duba HC, Gabriel C and Redl H: Labelling of human adipose-derived stem cells for non-invasive in vivo cell tracking. Cell Tissue Bank 8: 163-177, 2007.

41. Rice HE, Hsu EW, Sheng H, Evenson DA, Freemerman AJ, Safford KM, Provenzale JM, Warner DS and Johnson GA: Superparamagnetic iron oxide labeling and transplantation of adipose-derived stem cells in middle cerebral artery occlusion-injured mice. AJR Am J Roentgenol 188: 1101-1108, 2007.

42. Valina C, Pinkernell K, Song YH, Bai X, Sadat S, Campeau RJ, Le Jemtel TH and Alt E: Intracoronary administration of autologous adipose tissue-derived stem cells improves left ventricular function, perfusion and remodelling after acute myocardial infarction. Eur Heart J 28: 2667-2677, 2007.

43. Ripoll CB and Bunnell BA: Comparative characterization of mesenchymal stem cells from eGFP transgenic and non-transgenic mice. BMC Cell Biol 10: 3, 2009.

44. Yoshimura K, Sato K, Aoi N, Kurita M, Hirohi T and Harii K: Cell-assisted lipotransfer for cosmetic breast augmentation: Supportive use of adipose-derived stem/stromal cells. Aesthetic Plast Surg 32: 48-55; Discussion 56-57, 2008.

45. Kang JH, Gimble JM and Kaplan DL: In vitro 3D model for human vascularized adipose tissue. Tissue Eng Part A 15: 2227-2236, 2009.

46. Zuk PA: The adipose-derived stem cell: Looking back and looking ahead. Mol Biol Cell 21: 1783-1787, 2010.

47. Tobita M, Orbay H and Mizuno H: Adipose-derived stem cells: Current findings and future perspectives. Discov Med 11: 160-170, 2011.

48. Jiang T, Xu T, Gu F, Chen A, Xiao Z and Zhang D: Osteogenic effect of low intensity pulsed ultrasound on rat adipose-derived stem cells in vitro. J Huazhong Univ Sci Technolog Med Sci 32: 75-81, 2012.

49. Noer A, Boquest AC and Collas P: Dynamics of adipogenic promoter DNA methylation during clonal culture of human adipose stem cells to senescence. BMC Cell Biol 8: 18, 2007.

50. Utsunomiya T, Shimada M, Imura S, Morine Y, Ikemoto T, Mori H, Hanaoka J, Iwahashi S, Saito Y and Iwaguro H: Human adipose-derived stem cells: Potential clinical applications in surgery. Surg Today 41: 18-23, 2011.

51. Lin Y, Chen X, Yan Z, Liu L, Tang W, Zheng X, Li Z, Qiao J, $\mathrm{Li}$ S and Tian W: Multilineage differentiation of adipose-derived stromal cells from GFP transgenic mice. Mol Cell Biochem 285: 69-78, 2006.
52. Choi SA, Lee JY, Wang KC, Phi JH, Song SH, Song J and Kim SK: Human adipose tissue-derived mesenchymal stem cells: Characteristics and therapeutic potential as cellular vehicles for prodrug gene therapy against brainstem gliomas. Eur J Cancer 48: $129-137,2012$.

53. Zhao Y, Waldman SD and Flynn LE: The effect of serial passaging on the proliferation and differentiation of bovine adipose-derived stem cells. Cells Tissues Organs 195: 414-427, 2012.

54. Sharpless NE and DePinho RA: How stem cells age and why this makes us grow old. Nat Rev Mol Cell Biol 8: 703-713, 2007.

55. Pandey AC, Semon JA, Kaushal D, O'Sullivan RP, Glowacki J, Gimble JM and Bunnell BA: MicroRNA profiling reveals age-dependent differential expression of nuclear factor $\kappa \mathrm{B}$ and mitogen-activated protein kinase in adipose and bone marrow-derived human mesenchymal stem cells. Stem Cell Res Ther 2: 49, 2011.

56. Condé-Green A, Wu I, Graham I, Chae JJ, Drachenberg CB, Singh DP, Holton L III, Slezak S and Elisseeff J: Comparison of 3 techniques of fat grafting and cell-supplemented lipotransfer in athymic rats: A pilot study. Aesthet Surg J 33: 713-721, 2013

57. Neira R, Arroyave J, Ramirez H, Ortiz CL, Solarte E, Sequeda F and Gutierrez MI: Fat liquefaction: Effect of low-level laser energy on adipose tissue. Plast Reconstr Surg 110: 912-922; Discussion 923-925, 2002.

58. de la Fuente R, Bernad A, Garcia-Castro J, Martin MC and Cigudosa JC: Retraction: Spontaneous human adult stem cell transformation. Cancer Res 70: 6682, 2010.

59. Yoshimura K, Sato K, Aoi N, Kurita M, Inoue K, Suga H, Eto H, Kato H, Hirohi T and Harii K: Cell-assisted lipotransfer for facial lipoatrophy: Efficacy of clinical use of adipose-derived stem cells. Dermatol Surg 34: 1178-1185, 2008.

60. Coleman SR and Saboeiro AP: Fat grafting to the breast revisited: Safety and efficacy. Plast Reconstr Surg 119: 775-785; Discussion 786-787, 2007.

61. Yoshimura K, Asano Y, Aoi N, Kurita M, Oshima Y, Sato K, Inoue K, Suga H, Eto H, Kato H and Harii K: Progenitor-enriched adipose tissue transplantation as rescue for breast implant complications. Breast J 16: 169-175, 2010.

62. Peltoniemi HH, Salmi A, Miettinen S, Mannerström B, Saariniemi K, Mikkonen R, Kuokkanen H and Herold C: Stem cell enrichment does not warrant a higher graft survival in lipofilling of the breast: A prospective comparative study. J Plast Reconstr Aesthet Surg 66: 1494-1503, 2013.

63. Gentile P, Orlandi A, Scioli MG, Di Pasquali C, Bocchini I, Curcio CB, Floris M, Fiaschetti V, Floris R and Cervell V: A comparative translational study: The combined use of enhanced stromal vascular fraction and platelet-rich plasma improves fat grafting maintenance in breast reconstruction. Stem Cells Transl Med 1: 341-351, 2012

64. Doi K, Tanaka S, Iida H, Eto H, Kato H, Aoi N, Kuno S, Hirohi T and Yoshimura K: Stromal vascular fraction isolated from lipo-aspirates using an automated processing system: Bench and bed analysis. J Tissue Eng Regen Med 7: 864-870, 2013.

65. Kølle SF, Fischer-Nielsen A, Mathiasen AB, Elberg JJ, Oliveri RS, Glovinski PV, Kastrup J, Kirchhoff M, Rasmussen BS, Talman ML, et al: Enrichment of autologous fat grafts with ex-vivo expanded adipose tissue-derived stem cells for graft survival: A randomised placebo-controlled trial. Lancet 382: 1113-1120, 2013. 